\title{
Long term application of salicylic acid protects neuronal cells from hypoxia / reoxygenation injury in-vitro
}

\section{Zitta K., Gruenewald M., Schildhauer C., Steinfath M., Albrecht M.}

Department of Anesthesiology and Intensive Care Medicine, University Hospital Schleswig-Holstein, Campus Kiel, Germany.

Background: Aspirin and its major metabolite salicylic acid (SA) confer protection against glutamate neurotoxicity via COX dependent and independent mechanisms. There is also evidence that chronic stimulation with aspirin may protect against hypoxia-induced neuronal cell damage which is associated with increased levels of reactive oxygen species (ROS).

The aim of this study was i) to investigate the effects of chronically increased levels of salicylic acid on the ability of neuronal cells to survive hypoxia-induced neurotoxicity in-vitro and ii) to explore the underlying molecular mechanisms.

Materials and methods: Human neuronal IMR-32 cells were cultured with SA $(0.1,1$ and $10 \mu \mathrm{M})$ or with vehicle ethanol $(0.003 \%)$ as control for $2-7$ month. In-vitro hypoxia was induced for 3 hours using our recently described enzymatic system ${ }^{1,2}$. Cell morphology was evaluated by brightfield microscopy, cell damage was evaluated by lactate dehydrogenase $(\mathrm{LDH})$ assays. Production of ROS was analyzed using fluorometric assays with $2^{\prime}, 7^{\prime}$-dichlorofluorescein-diacetate $\left(\mathrm{H}_{2} \mathrm{DCFDA}\right)$. Westernblotting for catalase (CAT) and glutathione peroxidase (GPX) was performed, Fig. 1A.

Results: Long term incubation of neuronal IMR-32 cells with clinically relevant concentrations of SA $(0.1,1$ and $10 \mu \mathrm{M})$ did not change morphology of the cultures, Fig. 1B. However, neuronal cells that were exposed to chronic SA treatment showed statistically significant protection against hypoxia / reoxygenation injury (\#\#\#: P<0.001 vs. hypoxia control for all SA concentrations; hypoxia versus normoxia: *: $P<0.05 ;{ }^{* * *}: \mathrm{P}<0.001 ; \mathrm{n}=7$ ), Fig. 2A. A reduction in the production of ROS was observed only by $1 \mu \mathrm{M}$ SA, Fig. 2B. However, compared to control cells, protein expression of CAT, GPX were not altered in IMR-32 cells exposed to SA, Fig. 2C. Although the amount of CAT was not modify by the presence of SA, the specific inhibition of CAT activity by aminotriazole increased the hypoxia-induced cell damage $\left({ }^{*}: P<0.05\right.$ and ${ }^{* *}: P<0.01$ vs. $0 \mu M \quad S A ; \#: P<0.05$ vs. normoxia; \#\#: $P<0.01$ vs. normoxia; $\left.n=3\right)$, Fig. 2D.

A
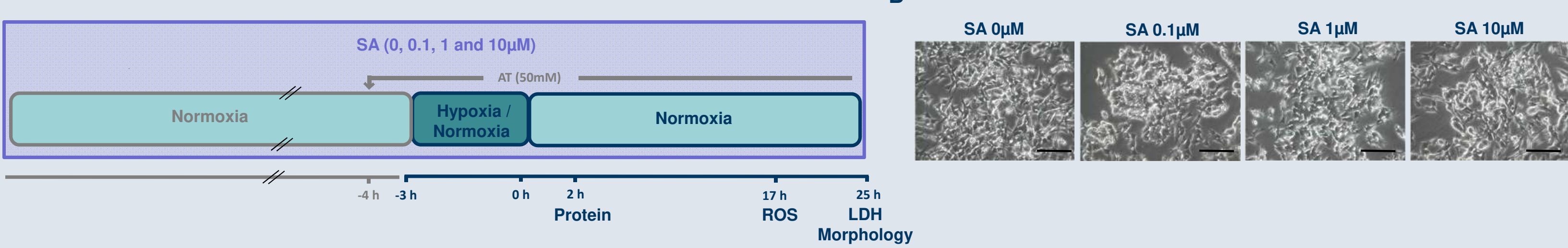

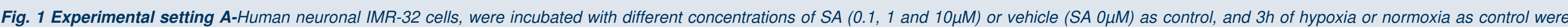
applied to the cells afterwards. At the end of the insult, fresh medium was added to the cultures. At different time points after hypoxia, intact cells, cell protein or the respective cell culture media were used to evaluate cell protein expression by westernblotting (at $2 \mathrm{~h}$ ), cell viability by LDH release (at 25h) and ROS production by DCFH-DA (at 17h). B- Cell morphology after long incubation with SA was evaluated by optical cell protein expression by westernblotting (at $2 h$ ), cell viability
microscopy at the end of the experiments. Bars denote $100 \mu \mathrm{M}$.
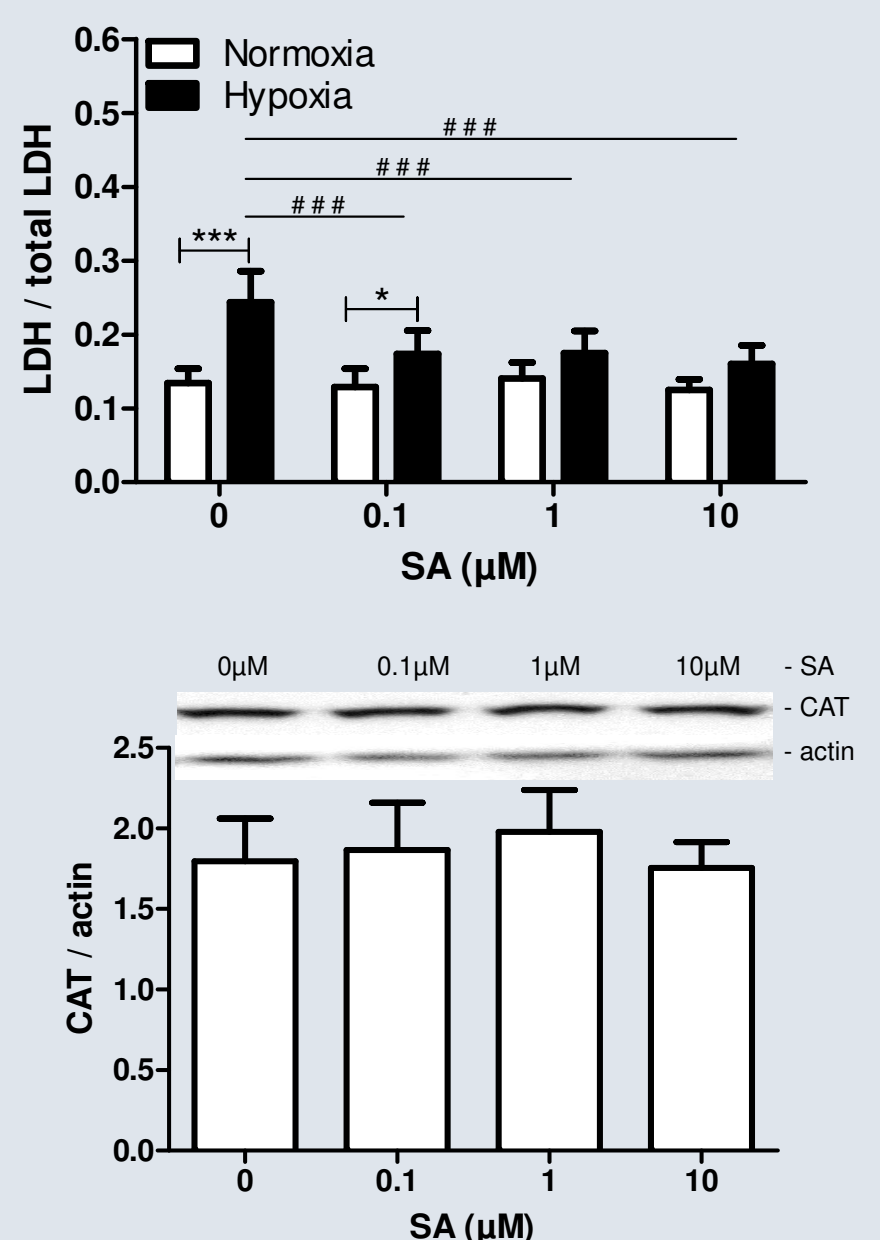

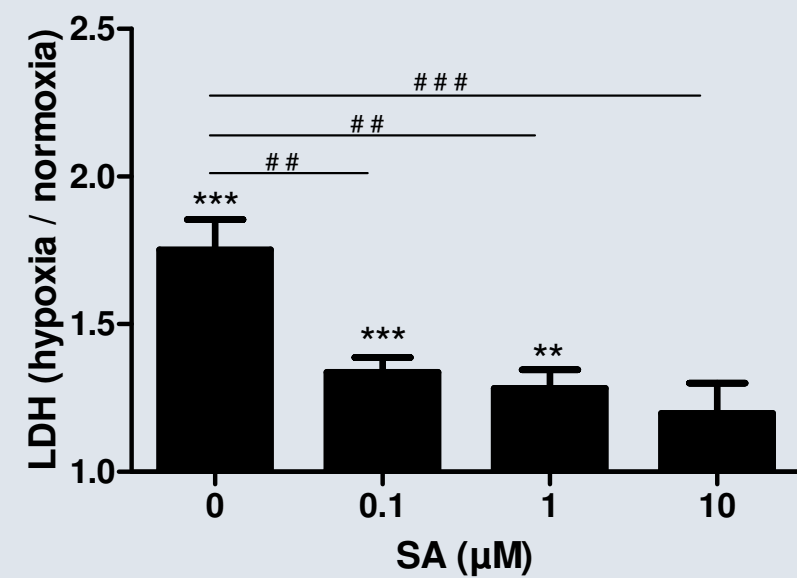

$0 \mu \mathrm{M} \quad 0.1 \mu \mathrm{M} \quad 1 \mu \mathrm{M} \quad 10 \mu \mathrm{M}-\mathrm{SA}$

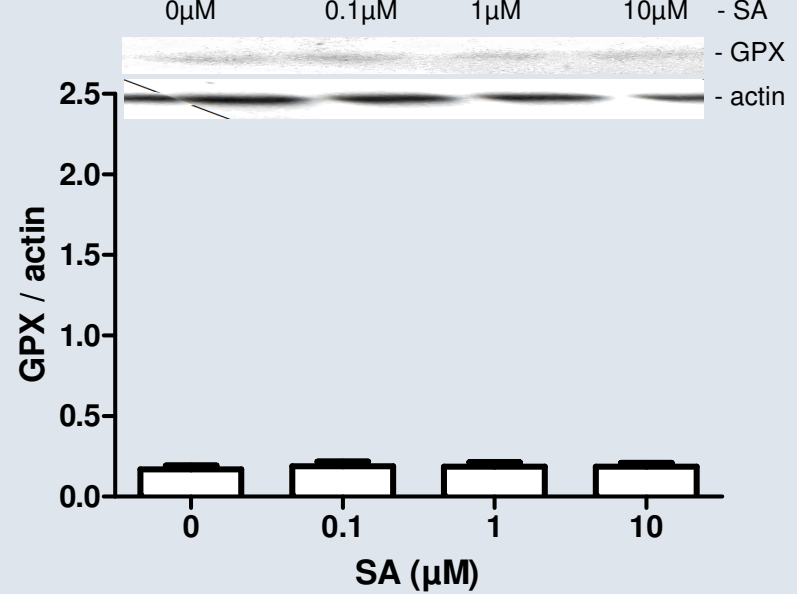

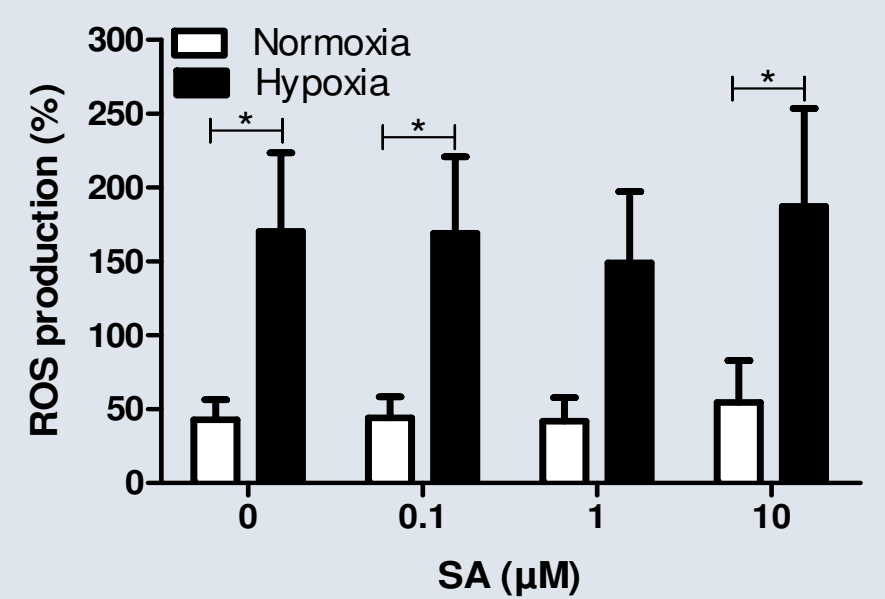

D

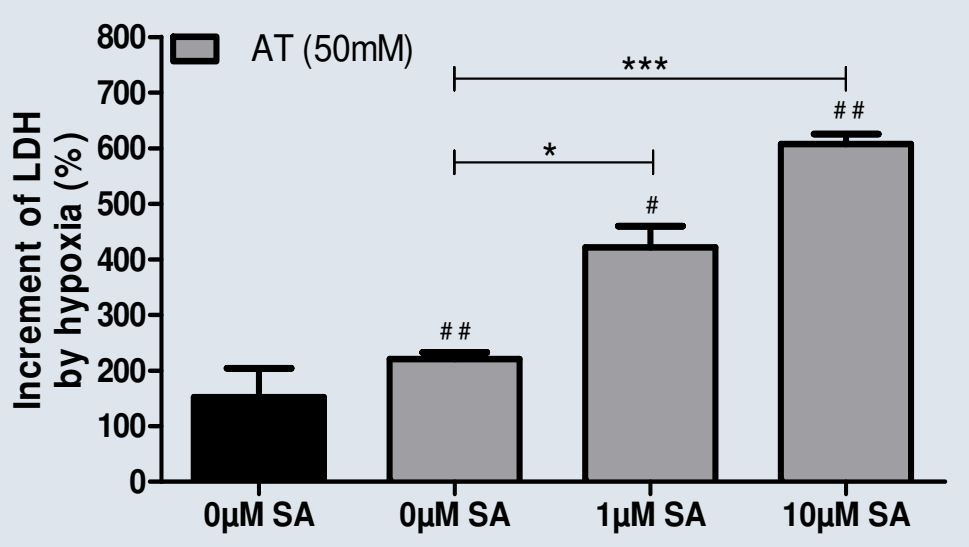

Fig. 2 Biochemical analyses A- IMR-32 were incubated with vehicle as control (SA OMM) or increasing concentrations of SA (0.1, 1 and $10 \mu \mathrm{M}$ in ethanol). An insult of $3 \mathrm{~h}$ hypoxia, was applied to the cells and the cell damage (by LDH release) was evaluated 25h after the insult. SA showed dose dependent protection against hypoxia. B-A diminution of the production of ROS was observed in cultures chronically exposed to $S A 1 \mu M$. C- Expression of redox related enzymes catalase (CAT) and glutathione peroxidase (GPX) were evaluated by westernblots using protein isolated $2 h$ after hypoxia. The protein expression of these enzymes did not show any modification by application of SA at the tested concentrations. D- The inhibition of CAT activity by aminotriazol (AT, 50mM) attenuated the protective effects of SA on hypoxia mediated cells damage.

\section{Conclusion:}

Long term treatment with salicylic acid induces neuronal resistance to hypoxia / reoxygenation injury and this effect may depend partially on catalase and ROS.

17. Titra et al. Exp. Cell Res. (2012) 318: 828-834.2Huang etal. Dis. Model Mech. (2013) 6(6): 1507-1514. 